\title{
Getting acquainted with the field
}

The dive luncheonette was just a couple of blocks from the Rutgers campus, but light years away from the doctoral program in urban planning where I was studying. Scratched tables, greasy food, and an irritable cook complemented the authentic atmosphere where I would regularly meet my professor/friend Frank Popper for cheap eggs and lukewarm coffee. None of the employees had any substantial formal education, and the clientele was largely blue collar construction workers helping to build a new university dorm down the street. But it was here that I discovered the field of shrinking cities.

Frank Popper was and still is a legend, and it was a great honor to study with him. Books have been written about his research on depopulation (and even a couple of movies). I may have been a bit star struck, but Popper's humble dress (sneakers and jeans) and disregard for the formalities of academia warmed our relationship. Along with his wife, he had proposed the outlandish idea that the Great Plains (nearly one-fifth of the land area of the U.S.) ought to be converted into a Buffalo Commons (see Figure 1.1). Through careful research and the boldness that comes with tenure, the Poppers initiated a profound shift in thinking in that region and elsewhere: maybe population decline does not have to be a bad thing if we can plan for future uses.

Over burnt toast and a side of hash browns, Popper and I debated and argued about this emerging shrinking cities field. A fortuitously timed trip for my part-time job to Michigan allowed me to take a short side trip to see the capital of U.S. shrinking cities: Detroit. Officially I was in the Wolverine State to see a shuttered lighthouse and meet with local officials, but I made special efforts to arrange for a visit to Detroit on the way to the airport.

To make the most of the visit, I first invested in identifying some contacts. Because Detroit was (in 2004) very much in the public eye 


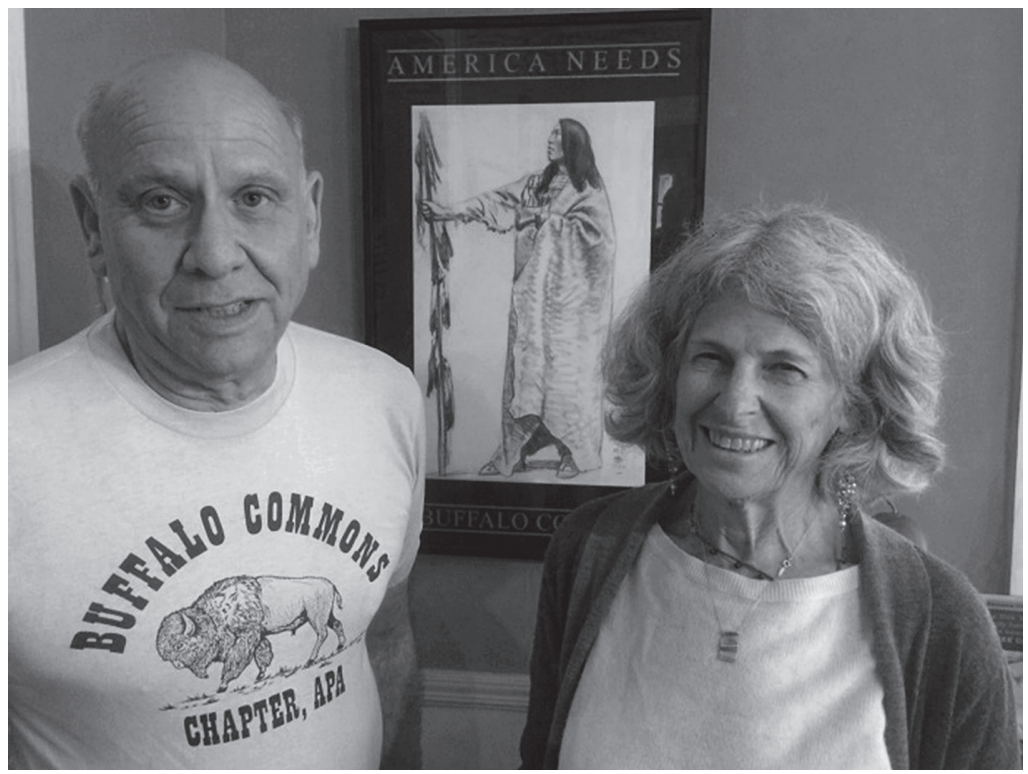

Figure 1.1 Frank and Deborah Popper, at their home in Highland Park, New Jersey

Source: Photo by Michael Milder, used with permission.

because of the impending incarceration of the Mayor, I eschewed the formal City Hall route and instead reached out to several neighborhood leaders. The only one who replied was John O'Brien of the Northwest Detroit Neighborhood Development. For about an hour, Mr. O'Brien drove me around the Brightmoor neighborhood of Detroit telling me about the history of the neighborhood and pointing out where they have been involved in demolition and rehabilitation.

"That one over there, a real shame, we just built it and got the family in there less than six months ago," John explained as he slowed down at a brand new single-family detached house with its upper floor charred from an apparent fire. Clad in bright colors, pastels and whites, this and other new or renovated homes were scattered amongst the poorly maintained and sometimes abandoned houses of the neighborhood. Built in the early 1920s, Brightmoor was intended as inexpensive housing for the throngs of new workers arriving in the city during the automobile manufacturing boom (Sugrue 1996, p.22). Low-quality 
materials and overall poor maintenance have led to widespread abandonment in the neighborhood for decades.

Immersing myself in this one neighborhood, I took tons of photographs and copious notes. Returning to New Jersey, I struggled to figure out how I, as a researcher, could make a difference for John O'Brien and the people of Brightmoor. Their situation was awful, millions of dollars had already been invested, and folks like John were working full-time, tirelessly to improve things. Who did I think I was to help, a skinny White kid from Connecticut? More importantly, what difference could research make?

That was over a decade ago, and I am happy to report that, dozens of research projects later, I finally have an answer. It is not a short and simple answer, but that is precisely why I am writing this book.

We are in this for the long haul. Researchers can and do provide immediate and direct assistance to advocates like John O'Brien and the residents of Brightmoor. In Chapter 6, I describe the ways that community action research can enhance and amplify the community benefits of such research. But those short-term and direct benefits are not at the core of the mission of researchers. Our aim is instead to contribute to broader and larger knowledge about why cities shrink, how they shrink, who is involved, what policies effectively address shrinkage, and what cities should do. To answer these kinds of questions means that we need to take our task seriously and invest for a long time horizon. To me, that was a difficult realization as I consider the kids playing in the vacant lot or the single mother who lives next to a vacant house occupied by drug dealers. To help these people, to solve the problems of the shrinking city, researchers need to ask those hard questions and answer them diligently, to consider questions all social scientists need to consider regarding research design, units of analysis, scale, validity, reliability, and generalizability. In this book, I offer my own experiences mixed with a review of other literature published on the shrinking cities topic. The result is a guide to doing research in this field: the best substitute I can offer for sharing a meal at that Jersey luncheonette.

In a 2013 New York Times story on Detroit's mayor, the reporter rhetorically asked the question: "Do services and infrastructure designed for all of this city's 139 square miles still make sense with a population of 700,000 and stretches of blocks where only a few houses remain occupied? Or must the city shrink to survive?" (Davey 2013, p. A1). 


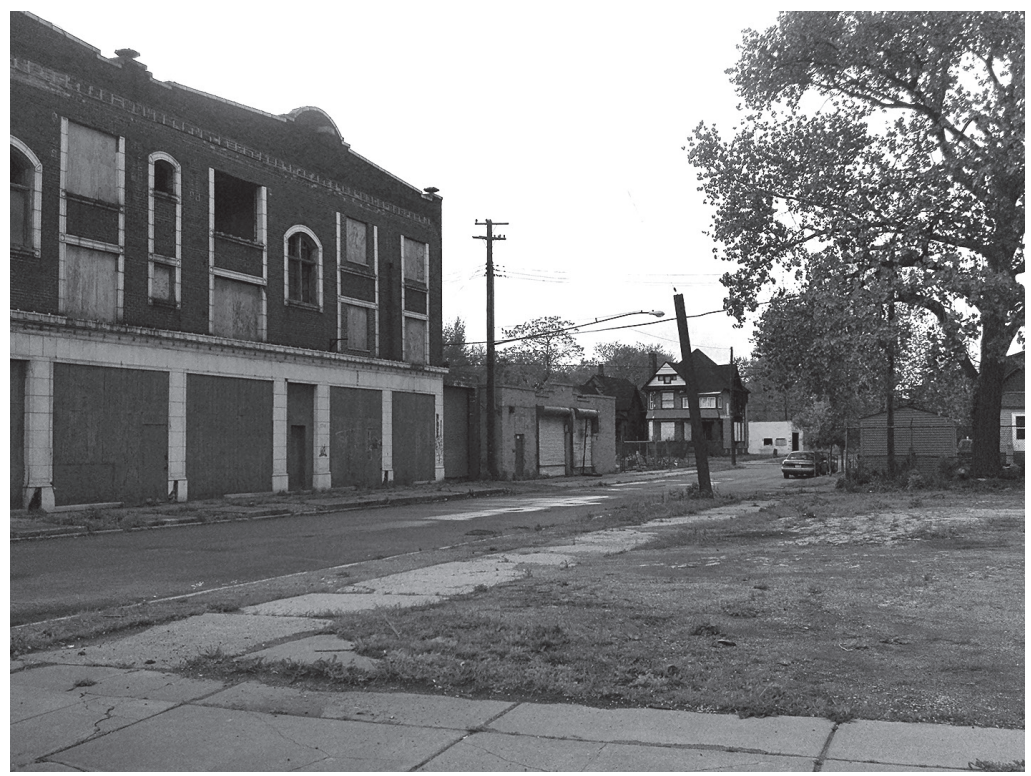

Figure 1.2 Empty lot in Delray, Detroit, Michigan

Source: Wikimedia Commons, https://commons.wikimedia.org/wiki/File:Abandoned BusinessesDelray.jpg; author: Notorious4life, public domain license.

Shrinking cities with neighborhoods littered with foreclosed and abandoned homes, empty factories, and little hope for the future face these same questions (see Figures 1.2 and 1.3). An emerging group of practitioners and scholars working under the umbrella of "shrinking cities" reject the growth-based paradigm that feeds much of urban planning and local government intervention (Oswalt 2006; Pallagst and Mercier 2007; Hollander et al. 2009; Hollander and Nemeth 2011). Rather than trying to grow every declining city, this approach argues that not all cities must grow back to their former glory. Instead of chasing industry with hefty incentives and the other standard economic development tools, for some cities it might be prudent to just focus on improving the quality of life for those left behind. For most cities, the idea would appear heretical. But the shrinking cities message today is salient and holds the potential to transform disaster into hope and promise.

But a myriad of issues arise in approaching research in this area. What is the right scale to study shrinkage: the region, metropolitan area, 


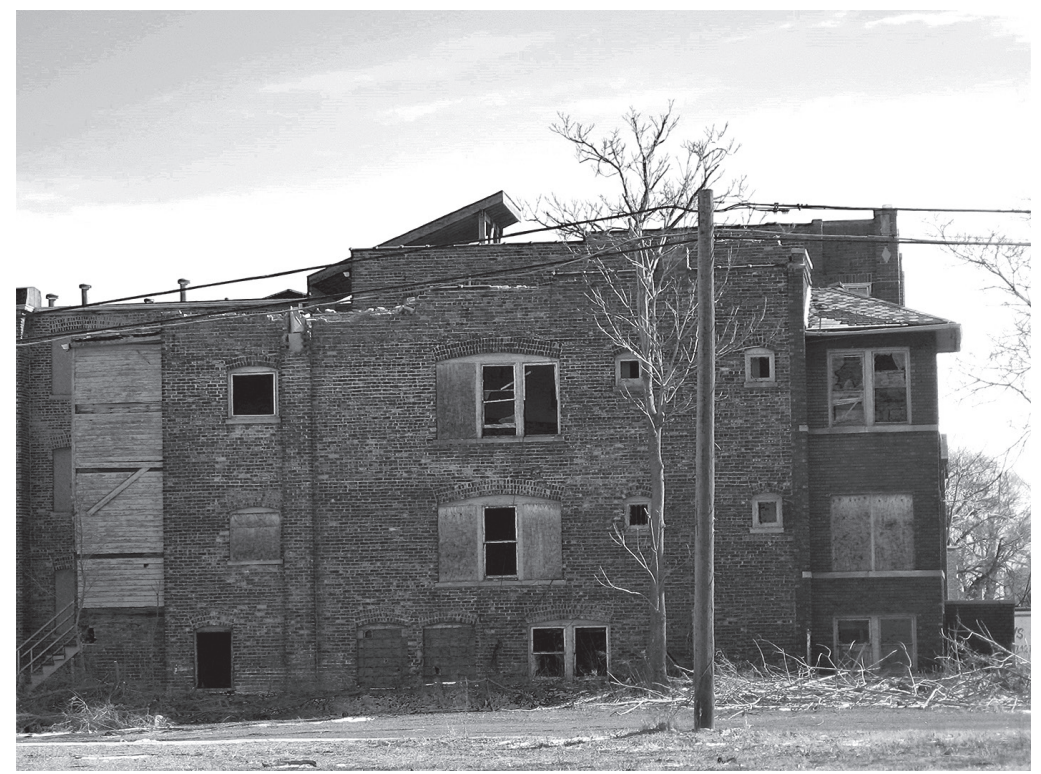

Figure 1.3 Abandoned apartment house in Gary, Indiana

Source: Wikimedia, https://commons.wikimedia.org/wiki/File:Abandoned_apartment_ house.JPG; author: Milwaukee3181; public domain.

local government, neighborhood, or block? What are the appropriate units of analysis for this type of research: should the focus be on individuals, families, communities, planners, local government agencies, or others? With all the attention on community action research in scholarly circles, what are the right ways for the "victims" of shrinking cities to be involved in the research process?

\section{Intellectual map of the field}

Fortunately, I am not the first to ask those questions above. Great thinkers and researchers across the social sciences and humanities have grappled with similar types of questions and offer a useful way to begin this work. Across political science, public policy, planning, geography, and architecture, scholars have engaged with debates around why cities decline, the goals of urban intervention, and what works and what does not in achieving a variety of goals. Not much 
agreement, but a lot of discussion and a lot of evidence. In a succinct, pithy, and wholly inadequate way, I offer in the rest of this chapter a distillation of that literature. It would take a doctoral dissertation to do that well. In fact, one of my fellow graduate students wrote a dissertation that included a nearly 100-page literature review out of a 200-page dissertation. Instead, I distilled from previous overviews I have written elsewhere (Sunburnt Cities, etc.) a concise summary that will offer some anchor points to connect with some key ideas presented later in the book. Additionally, it will provide a bit of a road map to help researchers in this field ground their own contributions.

\section{Why shrinkage happens and theories of intervention}

There is no single explanation as to why a place depopulates. Depopulation has been blamed on forces including natural disasters (Vale and Campanella 2005), deindustrialization (Bluestone and Harrison 1982; McDonald 2008) or post-industrialization (Highsmith 2007; Reckien and Martinez-Fernandez 2011; Martinez-Fernandez et al. 2012a; Wiechmann and Pallagst 2012; Hoekveld 2014), suburbanization (Jackson 1985; Clark 1989; Reckien and Martinez-Fernandez 2011; Martinez-Fernandez et al. 2012a; Hoekveld 2014), globalization (Sassen 1991; Hall 1997; Martinez-Fernandez et al. 2012a, 2012b, 2015), armed conflict and war (Rieniets 2009; Reckien and Martinez-Fernandez 2011), low birth rates (Reckien and Martinez-Fernandez 2011; Wiechmann and Pallagst 2012; Hoekveld 2014), and of course the natural economic cycle of boom and bust (Rust 1975; Ozatagan and Eraydin 2014). Beauregard's (2009) analysis of shrinking U.S. cities from 1820 to 2000 argued against such wholesale claims, concluding instead that causes of population decline vary from one historical period to another. A conference report from the Urban Affairs Association annual meeting affirmed that view, when a global group of scholars discouraged a "one-size-fits-all" explanation for why places lose population (Großmann et al. 2013).

The question of what causes cities to decline is hardly a settled one, though geographical uniqueness is probably the overriding constant. But at the neighborhood level there are two distinct bodies of thought on why depopulation happens: neighborhood life cycle theory and alternative neighborhood change theory (see Figure 1.4).

By viewing neighborhood change in terms of a life cycle, the first theory posits that places grow and die in a way analogous to the human body: "the constant cycle of birth, life, and death is inevitable in both" 


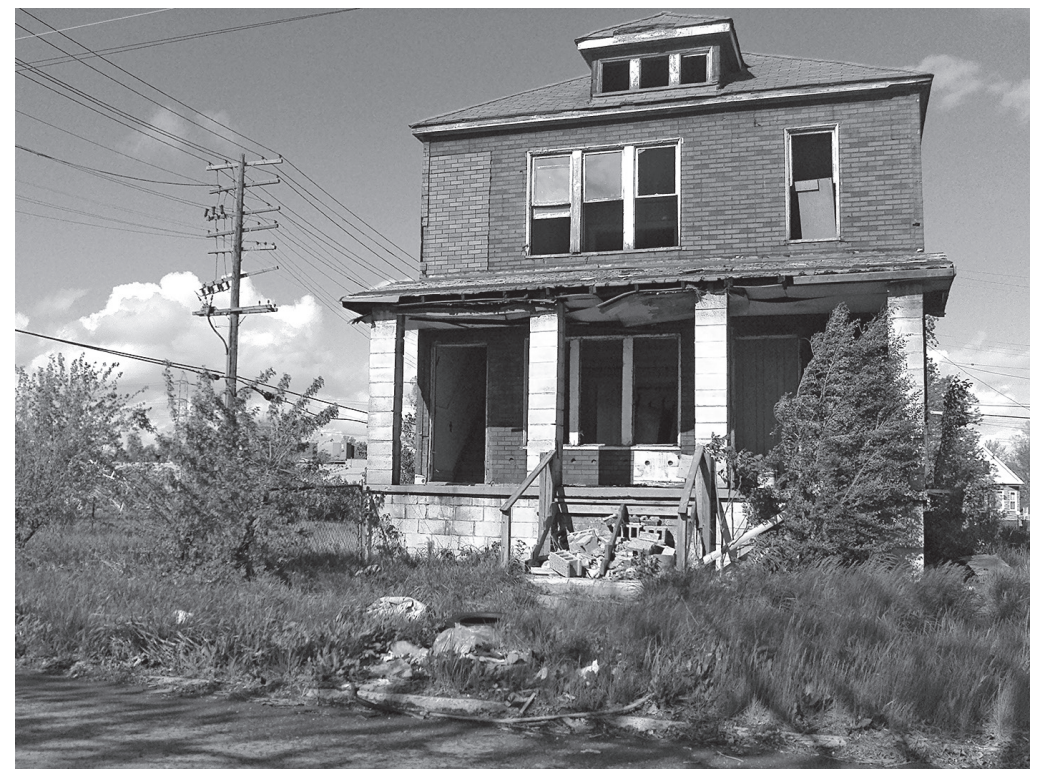

Figure 1.4 Abandoned house in Delray, Detroit, Michigan

Source: Wikimedia Commons, https://commons.wikimedia.org/wiki/File:Abandoned HouseDelray.jpg; author: Notorious4life; public domain license.

(United States Federal Home Loan Bank Board 1940, p. 3). Hoover and Vernon (1962) described five stages in a neighborhood's life cycle: new development, transition, downgrading, thinning-out, and renewal. The Real Estate Research Corporation (1975) outlined five similar steps along a continuum: healthy, incipient decline, clearly declining, accelerating decline, and abandoned.

Neighborhood life cycle theory was developed in order to better understand and rationalize the declining city. Many writing on the topic set out to identify planning and policy interventions that might either arrest or reverse this "natural" process (Bradbury et al. 1982).

The stated goal of policy makers was to help revitalize devastated places while preventing future deterioration of existing stable neighborhoods. Neighborhood life cycle theory has been tremendously influential in U.S. urban policy and planning, but has been subject to insightful critique (see Metzger 2000). 
Believing that such policies can arrest the slow death of neighborhoods, Blakely and Bradshaw (1994) and others in the economic development tradition draw on neighborhood life cycle theory in advocating public intervention through monetary investments in vacant land. Described as redevelopment or revitalization, this approach is often top-down in nature and uses forced relocation via eminent domain to achieve its objectives. A notorious example of this approach is the Boston Redevelopment Authority's urban renewal program in the West End of Boston (Gans 1962; Teaford 2000). More recently, the City of New London's Supreme Court victory allowed it to move forward with the condemnation of 64 privately owned homes in order to allow the expansion of a large corporation (Langdon 2005; Salzman and Mansnerus 2005). The Kelo v. City of New London, 125 S. Ct. 2655 (2005) case generated a groundswell of popular sentiment against eminent domain for the purposes of economic development and provoked a rash of new state laws and public protests against government taking of private property for economic development (Egan 2005).

This kind of top-down public intervention can be harmful in how it wrests control from local governments (Hospers 2013) and makes them ever more dependent on regional or national support (Mallach 2010; Martinez-Fernandez et al. 2015). Additionally, some authors argue that the growth hegemony can actually intensify the problems of depopulation (Bernt 2009; Hackworth 2014; Ozatagan and Eraydin 2014; Martinez-Fernandez et al. 2015).

The dominant interpretation of neighborhood life cycle theory is that public investment is needed to stop an out-of-control process. This view of neighborhood change fails to account for a scenario where a city loses population but does so without suffering the expected accompanying blight. Rather than look for ways to manage population loss so that blight does not occur, the theory only allows for the neighborhood to be seen as growing or declining, alive or dead (Hollander et al. 2009).

According to Metzger (2000), the future of a city depends not on its stage in a "natural" life cycle, "but on whether residents had access to financial resources within an environment of community control" (p.7). Metzger draws on a body of critical theory which rejects the modernist notions of advance and retreat, of growth and decline. Beauregard (2003) also explores this dialectic in examining the dis- 
course of urban decline. He finds that urban decline was incorporated into a socially constructed story of the rise of suburbia and fall of the city - a fictional account reified into the public consciousness through oral and written communication.

Critics such as Dear and Flusty (1998) advance a postmodern notion of neighborhood change that escapes this grand narrative and allows the details of each city, each neighborhood, and each block to speak for itself. Mitchell (2002) also contributes to this alternative theory in his account of planning in Egypt. He shows how the "informal, clandestine, and unreported" activities of society determined planning outcomes, not the "fabricated" script developed by Western colonizers. An understanding of urban decline as a disaggregated, finely complex phenomenon is possible under this alternative theoretical framework. This alternative theory of neighborhood change allows planners to be cognizant of urban problems, but to avoid the inevitability embedded in the discourse of urban decline. Such an unshackling from the structures of urban decline opens up the possibility for the planner to work towards proactively managing depopulation.

A planner or policy analyst drawing on this alternative theoretical framework may attempt creative intervention as described above, or may avoid action altogether. Hoch (1996) suggests that a consequence to postmodern planning practice is that a sense of hopelessness may infect the planner because all interventions are somehow intertwined with the forces of power. The planner who embraces alternative neighborhood change theories may be reluctant in labeling her city as "in decline," or might be timid about her own ability to manipulate power relations in an affected neighborhood.

Indeed, we can attribute much of the success of community development professionals in general, and community development corporations (CDCs) in particular, to their grounding in this alternative neighborhood change theory. For decades, CDCs and grassroots organizations have fought for a higher quality of life for residents of some of the poorest neighborhoods in America. For the most part, CDCs reject conventional views of neighborhood death and dying and instead promote new building and growth, often through the construction of new affordable housing. New movements are afoot, however, that recognize a certain inevitability of decline but plan for these demographic and socioeconomic shifts in proactive ways. 


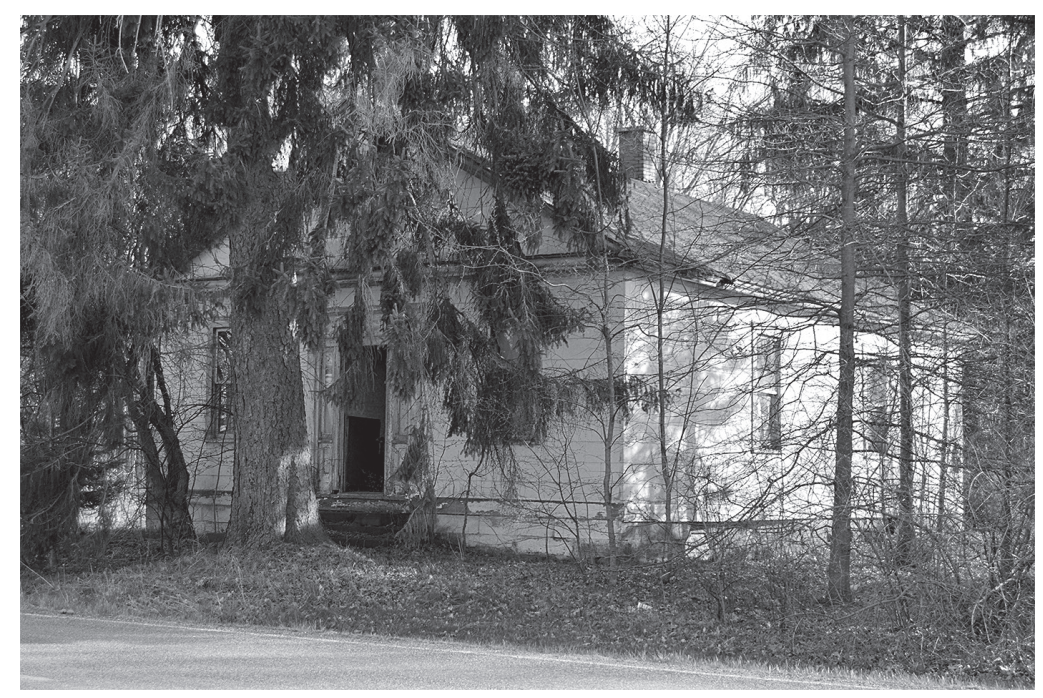

Figure 1.5 Abandoned house in Mercer County, Pennsylvania

Source: Wikimedia, https://commons.wikimedia.org/wiki/File:Amsterdam_abandoned_ GR_house.jpg; author: Nyttend; public domain.

\section{Other growth-oriented approaches to decline}

Not all planning and public policy is nicely grounded in grand theories; some policy solutions emerge more pragmatically out of the unique circumstances a community faces. Over the last decade, foreclosure reform, public-private partnerships, and land banks have emerged as reasonable policy responses to depopulation - though each does reflect some theoretical perspectives on neighborhood change.

During the Great Recession, with rampant foreclosures, many state and local governments began expediting the foreclosure process with the aim of getting vacant properties back into reuse (e.g. Michigan and Pennsylvania, U.S.A.) (Krohe 2011; Hackworth 2014) (see Figure 1.5). Here, the primary policy goals are around reoccupying empty homes largely a neighborhood life cycle response: people are being kicked out of their homes because they cannot afford their mortgages, banks take over these houses, and, because of the eyesores these buildings create, the neighborhood becomes increasingly less desirable - generating more foreclosures. According to neighborhood life cycle theory, the 
public intervention will arrest the foreclosure problem by getting homes reoccupied quickly.

Likewise, a number of recent initiatives to get local governments partnered with the private sector and civil society have yielded results in shrinking neighborhoods (Bernt 2009; Mallach 2010; Hospers 2013; Martinez-Fernandez et al. 2015). Where money is the problem, a funding gap is filled with unconventional (non-governmental) sources and the empty homes are reoccupied.

The third major policy trend is around land banks and somewhat straddles the two theoretical perspectives outlined above, neighborhood life cycle and alternative neighborhood change. Land banks are legally independent agencies that acquire and repurpose vacant and abandoned properties (Krohe 2011; Hackworth 2014; Morely 2015). They have been around for decades, but in 2002 in the county where Flint, Michigan is located, Genesee County, the county government formed a land bank explicitly to address the problem of vacant and abandoned properties due to long-term population decline (Alexander 2005; Schindler 2014). Led by then County Treasurer Dan Kildee, the Land Bank reversed the standard practice of letting tax-foreclosed abandoned homes languish in shrinking cities. "We have a 35-year history of letting so-called market forces deal with the problem of abandonment in cities, and we all know how well that worked out," Kildee told a reporter for Slate (Young 2010). Kildee succeeded in changing that, banking almost 80 percent of all properties that came his way, selling some new abutters and others to real estate developers. The Land Bank maintains most properties (with some help) through semiregular mowing.

What is remarkable about the Land Bank is that it is taking so much of the city's land off the market, which, in theory, pushes up the value of the rest of the city's land. One city official explained: "In Flint, the Land Bank owns 20 percent of the property, and they are totally on the board. I really think we're going to be on the cutting edge of cities." By taking land off-line for development, Kildee and now dozens of other local and state governments appear to be embracing the alternative neighborhood change theory, laying the groundwork for a smart shrinkage approach. 


\section{Top-down smart shrinkage}

Smart shrinkage is hardly a new idea. For at least 80 years, international cities have implemented various policies with mixed success. Below I present several examples of smart shrinkage processes: what these all have in common is that they were devised and implemented in a top-down manner, with little regard for the advances in bottom-up planning and policy approaches so widely accepted today.

In the United Kingdom before the outbreak of World War II, local government officials devised a strategy for shutting down mining towns in the countryside where mines had closed (Pattison 2004). Following the basic premise of smart shrinkage, the U.K. government saw widespread unemployment and declining population levels in a geographically concentrated area and reduced the number of homes, streets, and other infrastructure to meet that lower employment supply. Their top-down approach led to a major pushback from activists and residents, halting the program after only a single village was dismantled.

A similar program was developed by officials in New York City in the 1960 under the banner of triage planning and planned shrinkage. Facing fiscal disaster due to declining tax revenues associated with population loss, New York City Housing Commissioner Roger Starr led an effort to remove housing for the poorest residents and invest in the city's most economically viable areas (Sites 2003). Starr was ultimately removed from his position as a result of the political uproar his policies generated, but his ideas persisted: when the City of New York faced its worst fiscal crisis ever in the 1970s, planned shrinkage once again gained favor among the policy elite. Wallace and Wallace (1998) documented in fastidious detail how the City of New York, working with the RAND Corporation, orchestrated the closing of dozens of fire stations in parts of the city experiencing the highest depopulation levels. Their research demonstrates a strong causal link between those closures and the rampant arson and public health emergency that followed: with fewer fire stations, arsonists were emboldened and had little fear fires would be extinguished. The closure of fire stations in impoverished neighborhoods is indicative of the weakness of applying smart shrinkage from the top down.

This triage planning practice was not isolated to New York City, Schmidt's (2011) history of its use in Milwaukee in the 1970 s demon- 
strates the dangers of investing primarily in "savable" neighborhoods and largely writing off "unsavable" ones. One of the leading proponents of triage planning, Anthony Downs (1975), divided neighborhoods into those that were healthy, those beginning to transition to a state of decline, and those that were unhealthy. For those unhealthy neighborhoods, Downs recommended they "be targeted with job training, social services, and demolition of deteriorated housing" (Schmidt 2011, p.572). For those zones of Milwaukee which were unhealthy, the City committed to maintaining vacant land and associated public improvements, and "eliminating pockets of deterioration" - a euphemism for demolition. In addition, the City built physical barriers (2-foot tall timber and concrete pylons) along the street frontage of vacant lots to discourage illegal dumping.

The contemporary application of smart shrinkage in U.S. cities suggests the potential for a repetition of past top-down planning. While Youngstown's innovative Master Plan employed a bottom-up planning process, the implementation of the Plan so far is very much the opposite (Schatz 2010; Krohe 2011). In fact, my own research on the Youngstown experiment (Hollander 2009) shows that neighborhood district boundaries were drawn for the express purpose of limiting citizen participation in smart shrinkage strategies: some districts were created that were known to have few residents so that city officials could fully control land use decisions. While current public outreach efforts are stepping back from such a top-down posture, Youngstown Mayor Jay Williams set the tone early by boasting publicly about plans to pay residents to leave depopulating neighborhoods - even hinting at the potential use of the City's eminent domain powers (Schatz 2010).

More recently, Youngstown has made some strides in implementing its Plan and has used zoning and building codes to allow for more flexible reuse options (Morely 2015). The Relaxed Zoning Overlay tool, first introduced in my book Sunburnt Cities (Hollander 2011c) and later expanded on in a paper (Pantalone and Hollander 2012), is a good example of how a more flexible and dynamic zoning system provides potentially improved options for shrinking places. By relaxing zoning when a neighborhood begins to depopulate, new incentives are made available to repurpose residential land and buildings for nonresidential uses - uses that might ordinarily be prohibited for a purely residential district. 


\section{The genesis and maturity of the shrinkage idea}

In the last few decades, mass migration from the former East Germany to West Germany following the fall of the Berlin Wall has left cities and towns emptied. The German Federal Cultural Council responded in 2004 by funding an arts-grounded Shrinking Cities Project (Oswalt 2006). The Project included an international ideas competition that generated scores of ideas on how to make smart decline happen - in the process defining the scope of the problem and outlining the boundaries of policy and planning responses - initiating a sketch of what smart decline looks like.

The Shrinking Cities Project then spawned a traveling exhibit showcasing these novel ideas in dozens of cities throughout the world. The interest created by the Project resulted in a conference on the topic sponsored by Kent State University in 2005 and another in 2006 convened by a newly formed group at the University of California, Berkeley, Shrinking Cities in a Global Perspective (Pallagst 2008).

While academics and artists were singing the praises of shrinkage, the popular media was slow to catch on. In fact, for some years after the German event, the media was still using the same old language of decline as death. Forbes Magazine, which loves to rank the best and worst of everything, the richest CEOs, the best place to vacation, the worst places to work, may have hit a new low by profiling the FastestDying Cities in its August 2008 issue (Zumbrun 2008). The issue took specific aim at: Buffalo, NY; Canton, OH; Charleston, WV; Cleveland, $\mathrm{OH}$; Dayton, OH; Detroit, MI; Flint, MI; Scranton, PA; Springfield, $\mathrm{MA}$; and Youngstown, $\mathrm{OH}$.

So, hurt and inspired by such a label, activists in Dayton, $\mathrm{OH}$ decided to fight back. Co-opting the term "dying" they organized local officials and activists for a Forbes 10 Fastest-Dying Cities Symposium and Art Exhibition held in August 2009. Over 200 people from eight of the ten cities attended, celebrating what is good and alive about their cities, like spirit and passion, dimensions not so easily calculated in Forbes's statistical analysis. Dayton's city planner argued for a shrinking cities approach to city planning: "The future in front of us is different from what we knew in the past. We won't recreate the Dayton of the'5os and'6os" (Hollander 2011c).

The Brookings Institution tried a few years before the "dying cities" ruckus to rebrand declining cities as "weak market cities." Their 
effort garnered some attention and helped somewhat to reframe the discussion around depopulation (Burnett 2003). More recently, Brookings issued two reports on what the federal government should do about shrinkage (Mallach 2010) and a policy guide directed specifically at Ohio local and state governments (Mallach and Brachman 2010).

The federal report called for a rethinking of the concept of affordable housing in shrinking cities, questioning what is gained by providing government-subsidized affordable housing (through the low-income tax credit program) in places where market-rate housing is already quite affordable. The result, the report author argues, is the proliferation of new, federally subsidized affordable housing in areas desperately in need of reducing the number of housing units to meet a smaller population.

Mallach (2010) also criticizes U.S. Department of Housing and Urban Development (HUD) policies that require an annual consolidated plan without any meaningful consideration of future demographic change. Mallach (2010) calls for new HUD language that requires communities to design "targeted strategies for reconfiguration of land uses and economic activity around the reality of population loss" (p. 27). The Ohio report echoes some of the same themes as the federal report, adding the need for state and local policies to promote urban agriculture and land banking.

The Federal Reserve Bank (FRB) also toyed around with the benefits of shrinkage. The FRB of Cleveland produced a report in 2008 which held the Youngstown planning example up as good practice and called for demolishing homes that are vacant. The recommendations were intended to fix a broken housing cycle that occurs in a period of economic malaise. The FRB of Cleveland is on record for arguing that demolition of vacant housing is an effective way to break this cycle of crisis and to help stabilize neighborhoods. It is a radical policy recommendation to call for destroying sound structures that could help meet society's housing needs. But at the very core of the shrinking cities idea is that the need of neighborhoods to maintain some kind of equilibrium in their housing market trumps policies that purport to increase the stock of affordable housing. If we cannot stabilize the physical changes occurring in shrinking by managing them (through demolition, reconfiguration, or reuse), the FRB of Cleveland and the Brookings Institution argue, the overall quality of life in these places 
will fall so low that these new affordable housing units will be quite undesirable.

Interestingly, the historic preservation field has led this kind of creative thinking in the U.S., reconceptualizing decline and focusing planning efforts around preservation as the key to good smart shrinkage. The Advisory Council on Historic Preservation published a useful report, Historic Preservation and Rightsizing: Current Practices and Resources Survey (Bertron and Rypkema 2012), documenting local government official attitudes towards rightsizing, smart shrinkage, and historic preservation. The report spawned the creation a couple of years later of the Preservation Rightsizing Network, which sponsors events and networking around these issues.

Efforts have been even more robust in recent years in Europe, where the European Union has funded a multitude of research and policy efforts to address depopulation. One notable project, Shrink Smart, was active from 2009 to 2012, hosting events and conducting research on depopulation issues throughout Europe. Likewise, the Organisation for Economic Co-operation and Development (OECD) ran an intensive research program during roughly the same period under the banner "Demographic Change and Local Development: Shrinkage, Regeneration and Social Dynamics." One of the products of that research is the focus of a close reading in Chapter 2.

\section{Outline of the remainder of the book}

With a quick overview of the intellectual terrain of shrinking cities behind us, the next six chapters each cover a sub-domain within shrinking cities. For each of Chapters 2 to 7 I offer a quick overview of the topics, relevant problems and paradoxes, and key research questions. These chapters conclude with a discussion of the methods a researcher might employ to answer these research questions and a profiling of one study in-depth. The sub-domains include: regional perspectives, local government, residential neighborhoods, downtowns, social equity, and defining success. I end the book by reviewing the major themes already explored and look to the future, anticipating the most significant research trends related to shrinking cities.

Studying the problems of growing cities is easy. You have the entire real estate development apparatus, the engineers, architects, landscape 
architects, geologists, bankers, and lawyers behind you. A veritable "growth machine" ${ }^{1}$ of academics, scientists, and political leaders love to study the problems of growth, sprawl, and related issues. No such army exists to support and reinforce the study of shrinking cities. This book is an effort to provide some of that support, some infrastructure to help researchers examine the key questions that shrinking cities face. The more difficult task will be to answer those questions, with rigor, to arrive at valid and reliable results that are generalizable - for that I hope this book helps.

NOTE

1 The growth machine reference here is to Logan and Molotch's seminal 1987 book. 